\title{
Mesenchymal stem cell-derived conditioned medium protects vascular grafts of brain-dead rats against in vitro ischemia/reperfusion injury
}

Sevil Korkmaz-Icöz ${ }^{1 *}$, Pengyu Zhou', Yuxing Guo ${ }^{1}$, Sivakkanan Loganathan², Paige Brlecic ${ }^{1}$, Tamás Radovits ${ }^{3}$, Alex Ali Sayour ${ }^{1,3}$, Mihály Ruppert ${ }^{1,3}$, Gábor Veres ${ }^{1,2}$, Matthias Karck ${ }^{1}$ and Gábor Szabó ${ }^{1,2}$

\begin{abstract}
Background: Brain death (BD) has been suggested to induce coronary endothelial dysfunction. Ischemia/ reperfusion (IR) injury during heart transplantation may lead to further damage of the endothelium. Previous studies have shown protective effects of conditioned medium (CM) from bone marrow-derived mesenchymal stem cells (MSCs) against IR injury. We hypothesized that physiological saline-supplemented CM protects BD rats' vascular grafts from IR injury.

Methods: The CM from rat MSCs, used for conservation purposes, indicates the presence of 23 factors involved in apoptosis, inflammation, and oxidative stress. BD was induced by an intracranial-balloon. Controls were subjected to a sham operation. After $5.5 \mathrm{~h}$, arterial pressures were measured in vivo. Aortic rings from $\mathrm{BD}$ rats were harvested and immediately mounted in organ bath chambers (BD group, $n=7$ ) or preserved for $24 \mathrm{~h}$ in $4^{\circ} \mathrm{C}$ salinesupplemented either with a vehicle (BD-IR group, $n=8$ ) or CM (BD-IR+CM group, $n=8)$, prior to mounting. Vascular function was measured in vitro. Furthermore, immunohistochemistry and quantitative real-time polymerase chain reaction (qRT-PCR) have been performed.

Results: $\mathrm{BD}$ in donors was associated with significantly impaired hemodynamic parameters and higher immunoreactivity of aortic myeloperoxidase (MPO), nitrotyrosine, caspase-3, caspase-8, caspase-9, and caspase-12 compared to sham-operated rats. In organ bath experiments, impaired endothelium-dependent vasorelaxation to acetylcholine in the BD-IR group compared to $\mathrm{BD}$ rats was significantly improved by $\mathrm{CM}$ (maximum relaxation to acetylcholine: $\mathrm{BD} 81 \pm 2 \%$ vs. BD-IR $50 \pm 3 \%$ vs. BD-IR $+\mathrm{CM} 72 \pm 2 \%, p<0.05$ ). Additionally, the preservation of BD-IR aortic rings with CM significantly lowered MPO, caspase-3, caspase-8, and caspase-9 immunoreactivity compared with the BD-IR group. Furthermore, increased mRNA expression of vascular cell adhesion molecule (VCAM)-1 and intercellular adhesion molecule (ICAM)-1 in the aortas from the BD-IR rats compared to BD group were significantly decreased by $\mathrm{CM}$.

(Continued on next page)
\end{abstract}

\footnotetext{
*Correspondence: korkmaz@uni-heidelberg.de

'Department of Cardiac Surgery, Laboratory of Cardiac Surgery, University Hospital Heidelberg, INF 326, 69120 Heidelberg, Germany

Full list of author information is available at the end of the article
}

(C) The Author(s). 2021 Open Access This article is licensed under a Creative Commons Attribution 4.0 International License, which permits use, sharing, adaptation, distribution and reproduction in any medium or format, as long as you give appropriate credit to the original author(s) and the source, provide a link to the Creative Commons licence, and indicate if changes were made. The images or other third party material in this article are included in the article's Creative Commons licence, unless indicated otherwise in a credit line to the material. If material is not included in the article's Creative Commons licence and your intended use is not permitted by statutory regulation or exceeds the permitted use, you will need to obtain permission directly from the copyright holder. To view a copy of this licence, visit http://creativecommons.org/licenses/by/4.0/ The Creative Commons Public Domain Dedication waiver (http://creativecommons.org/publicdomain/zero/1.0/) applies to the data made available in this article, unless otherwise stated in a credit line to the data. 
(Continued from previous page)

Conclusions: The preservation of BD rats' vascular grafts with CM alleviates endothelial dysfunction following IR injury, in part, by reducing levels of inflammatory response and caspase-mediated apoptosis.

Keywords: Ischemia/reperfusion, Endothelial function, Mesenchymal stem cells, Conditioned medium, Brain death

\section{Introduction}

Heart transplantation remains the therapy of choice for patients with refractory heart failure [1]. Currently, hearts are mainly procured from brain-dead (BD) donors. However, coronary endothelial dysfunction is welldescribed after cardiac transplantation [2] and has been also suggested following brain death [3]. Usually, brain death is a consequence of increased intracranial pressure, which initially causes compensatory arterial hypertension to maintain adequate cerebral perfusion pressure, tachycardia, and intense peripheral vasoconstriction due to an early catecholamine storm [4]. After this hypertensive phase, there is a loss of sympathetic tone and subsequent peripheral vasodilation, resulting in hypotension [5]. Furthermore, brain death triggers inflammatory response. In heart transplantation, ischemia/ reperfusion (IR) injury is a major issue. IR-induced disturbance of the endothelium's functional integrity, known as "endothelial dysfunction," is caused by the rapid normalization of the acidotic $\mathrm{pH}$ following reperfusion, which initiates the depletion of high-energy phosphates [6], high production of reactive oxygen species (ROS), the generation of inflammatory cytokines and infiltrating neutrophils [7], and finally leads to cell death [8]. The role of acidosis was evidenced by ischemic acidosis-induced apoptosis in coronary endothelial cells of arteries through activation of caspase-12 and caspase-3 [9]. Thus, any pre-existent vascular damage due to brain death may be aggravated by hypothermic preservation/warm reperfusion during transplantation. Taken together, the significance of vascular endothelial dysfunction makes the endothelium an attractive target during the perioperative management of heart transplantation. However, endothelial structural and functional integrity under conditions of organ preservation following brain death have not been extensively investigated [10]. Therefore, further studies are warranted to identify novel strategies to prevent adverse effects of IR injury and brain death, not only for cardiomyocytes but also the endothelium, so that endothelial protection could be shifted into cardiac protection.

Bone marrow-derived mesenchymal stem cells (MSCs), multipotent and self-renewing cells [11], are emerging as a promising cell-based therapy for IR-induced myocardial infarction [12, 13]. The potential therapeutic effects of MSCs have been attributed to their excellent properties in immunomodulation, angiogenesis, the capacity to differentiate into multiple tissue types, the ability to engraft into injured tissue, and direct cell-to-cell contact [14]. However, recent studies have revealed that the long-term survival rate of implanted MSCs is relatively low $[15,16]$, suggesting an alternative mode of repair, including paracrine mechanisms [17]. An increasing number of literature brought attention to the vast array of factors produced by MSCs, such as chemokines/cytokines [18] and anti-apoptotic and growth factors, which could play a significant protective role $[19,20]$. A previous ex vivo study reported that conditioned medium (CM) from bone marrow-derived MSCs added at the onset of reperfusion following ischemia conferred protection against myocardial IR injury [21]. The protection induced by $\mathrm{CM}$ included attenuation of apoptosis and oxidative stress in the heart [22]. We have shown that the presence of $\mathrm{CM}$ in preservation solution during prolonged ischemic time improves functional post-transplant graft recovery in 15-month-old rats [23]. Furthermore, our recent in vivo study provides experimental evidence that the preservation of $\mathrm{BD}$ donor hearts with cardioplegic solution enriched with CM improves graft contractility after heart transplantation [24].

Taken together, we hypothesized that physiological saline solution-supplemented $\mathrm{CM}$ protects vascular grafts of BD rats from IR injury. Next, we explored the potential molecular mechanisms underlying the beneficial effect of CM on endothelial dysfunction due to both IR injury and brain death. We investigated its link to nitrooxidative stress, inflammation, and apoptosis.

\section{Materials and methods}

See the Online Appendix for further details.

\section{Animals}

Inbred male Lewis rats (8-12 weeks old; Janvier Labs, Saint Berthevin, France) received care in compliance with the Guide for the Care and Use of Laboratory Animals (National Institutes of Health Publication No. 8523, revised 1996). All procedures and handling of animals during the investigations were reviewed and approved by the Ethical Committee of the Regional Council of Karlsruhe, Land Baden-Württemberg for Animal Experimentation (G37/14). The animals were housed at constant ambient temperature $\left(22 \pm 2{ }^{\circ} \mathrm{C}\right)$ in light-controlled rooms (12-12 h light-dark cycles), were given food and water access ad libitum, and were acclimatized for 1 week. 


\section{Preparation of bone marrow-derived MSCs-CM}

As previously reported [25], rats were euthanized with an overdose of pentobarbital sodium $(100 \mathrm{mg} / \mathrm{kg}$, intraperitoneally). The bone marrow was isolated by flushing the femurs and tibias with Dulbecco's phosphatebuffered saline (DPBS) (Sigma, St. Louis, MO, USA). The cells were suspended in MSC Expansion Medium (R\&D System, Minneapolis, MN, USA) and then incubated at $37{ }^{\circ} \mathrm{C}$ with $5 \% \mathrm{CO}_{2}$ on cell culture flasks. Primary cells were subcultured 1:3 when $80 \%$ confluency was reached. After MSCs reached greater than $80 \%$ confluency at passage 3 , the medium was aspirated, and MSCs were rinsed 3 times with DPBS. Then, Dulbecco's modified Eagle's medium (D-MEM) (Life Technologies, Grand Island, NY, USA) was added to culture dishes with MSCs, and the culture dishes were put into an incubator for $24 \mathrm{~h}$. Primary CM was collected and centrifuged by ultrafiltration units $\left(4500 \mathrm{~g}\right.$ for $4 \mathrm{~h}$ at $\left.4{ }^{\circ} \mathrm{C}\right)$ to yield concentrated CM. A simplified schematic of the MSCs-CM collection protocol is shown in Fig. 1. The protein concentration of the $\mathrm{CM}$ was quantified by Bradford protein assay to ensure that equal concentrations $(0.5 \mathrm{mg} / \mathrm{mL})$ of $\mathrm{CM}$ was used. D-MEM was regarded as a control (nonconditioned medium).

\section{Screening of secreted proteins in CM}

The cytokines/chemokines of isolated CM were qualitatively measured by using Rat Antibody Array 90 (RayBiotech, Norcross, GA).

\section{Model of brain death}

As previously reported [26, 27], the rats were anesthetized with pentobarbital sodium $(60 \mathrm{mg} / \mathrm{kg}$, intraperitoneally), then intubated and ventilated by a rodent respirator (Harvard Apparatus, Holliston, MA, USA). The right carotid artery and left external jugular vein were cannulated for pressure monitoring (Micromanometer catheter, Millar Instruments, Houston, TX, USA) and ringer infusion, respectively. The body temperature (measured via a rectal probe) was maintained between 36.5 and $37.5^{\circ} \mathrm{C}$ with a heat mat. A small $4 \mathrm{~F}$ burr hole was drilled into the parietal skull, and a balloon catheter was introduced subdurally and inflated with $15 \mu \mathrm{L}$ of saline per minute until a total volume of $600 \mu \mathrm{L}$ was reached. The state of brain death was confirmed by the sustained absence of spontaneous breathing and brainstem reflexes. After reaching the final volume, the blood pressure was stabilized. A drop of blood pressure $<60$ $\mathrm{mmHg}$ was avoided by volume administration using ringer solution without inotropic or vasoactive agents. Control donor rats were subjected to a sham operation. Sham-operated and BD donors underwent continuous hemodynamic monitoring for $5.5 \mathrm{~h}$.

\section{Model of vascular dysfunction induced by ischemic storage and reperfusion Preparation of isolated thoracic aortic rings}

At $5.5 \mathrm{~h}$ post-sham operation or brain death, the thoracic aorta was explanted and immediately placed in cold $\left(4{ }^{\circ} \mathrm{C}\right)$ Krebs-Henseleit solution (KHL) $(118 \mathrm{mM} \mathrm{NaCl}$,

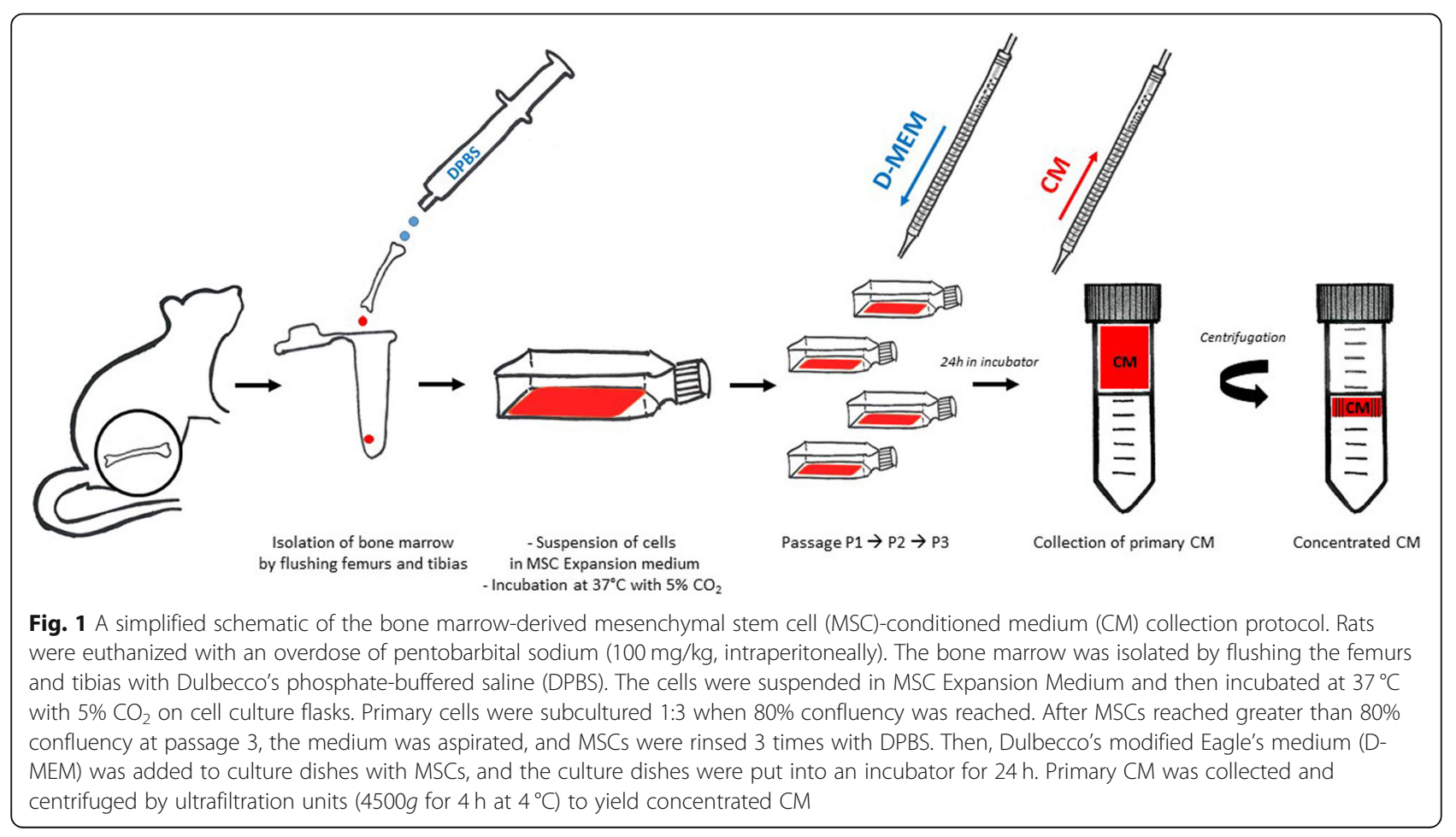


$4.7 \mathrm{mM} \mathrm{KCl}, 1.2 \mathrm{mM} \quad \mathrm{KH}_{2} \mathrm{PO}_{4}, 1.2 \mathrm{mM} \mathrm{MgSO}_{4}, 1.77$ $\mathrm{mM} \mathrm{CaCl} 2,25 \mathrm{mM} \mathrm{NaHCO} 3,11.4 \mathrm{mM}$ glucose; $\mathrm{pH}$ 7.4) and treated with $95 \% \mathrm{O}_{2}-5 \% \mathrm{CO}_{2}$. After careful dissection of adhering fat and connective tissue without damaging the endothelium, the aorta was cut into several segments (each $4 \mathrm{~mm}$ in length).

\section{Experimental groups}

As previously reported [28], physiological saline was treated with nitrogen to extrude oxygen from the solution. Then, the aortic rings were placed in closed, airfree tubes filled with saline supplemented with either DMEM vehicle [BD-IR ( $n=8$ rats, 32 rings) group] or CM [BD-IR+CM ( $n=8$ rats, 32 rings) group] and stored for $24 \mathrm{~h}$ at $4{ }^{\circ} \mathrm{C}$. After cold ischemic conservation, the rings were mounted in organ bath chambers. To simulate free radical burst and endothelial dysfunction, which usually occurs during reperfusion in vivo, hypochlorite was added to the baths $(200 \mu \mathrm{M}, 30 \mathrm{~min})$. Aortic rings in the sham ( $n=7$ rats, 24 rings) and $\mathrm{BD}(n=8$ rats, 26 rings) normoxia groups did not undergo cold ischemic storage but were immediately mounted in organ baths after their preparation.

\section{In vitro organ Bath experiment}

Aortic rings were mounted on stainless steel hooks in organ baths (Emka Technologies, Paris, France), containing $20 \mathrm{~mL}$ of $\mathrm{KHL}$ and continuously treated with $95 \%$ $\mathrm{O}_{2}-5 \% \mathrm{CO}_{2}$ at $37^{\circ} \mathrm{C}$. The rings were placed under an optimal resting tension of $2 \mathrm{~g}$ for $60 \mathrm{~min}$ for equilibration. During this period, the tension was cyclically adjusted to the $2 \mathrm{~g}$ resting tension, and KHL was replaced every $30 \mathrm{~min}$. After the equilibration period, the stretched rings were contracted with potassium chloride $(\mathrm{KCl}, 80 \mathrm{mM})$ to obtain maximal contraction forces. Then, the aortic rings were washed to acquire resting tension again. Relaxation responses were examined with the endothelium-dependent vasorelaxant acetylcholine (ACh) and the endothelium-independent vasorelaxant agent sodium nitroprusside (SNP). Briefly, aortic rings were precontracted with phenylephrine $\left(\mathrm{PE}, 10^{-9}-10^{-5}\right.$ $\mathrm{M})$ until a stable plateau was reached. Relaxation responses were obtained by the addition of cumulative concentrations of ACh $\left(10^{-9}-10^{-4} \mathrm{M}\right)$. Then, the aortic rings were washed to obtain resting tension, and $\mathrm{PE}$ $\left(10^{-6} \mathrm{M}\right)$ was added to the organ baths until a new, stable plateau was reached. At last, SNP $\left(10^{-10}-5 \times\right.$ $10^{-7} \mathrm{M}$ ) was applied to test the relaxation response of smooth muscle cells. The tension was recorded with isometric force transducers of a myograph (159901A; Radnoti Glass Technology, Monrovia, CA, USA), digitized, and displayed with the IOX Software System (EMKA Technologies, Paris, France). Contractile responses to $\mathrm{KCl}$ were described in grams of tension, and contractile responses to PE were expressed as a percent of the maximum contraction induced by $\mathrm{KCl}$. By fitting experimental data to a sigmoidal equation using Origin 7.0 (Microcal Software Northampton, MA, USA), halfmaximum response $\left(\mathrm{EC}_{50}\right)$ values were generated from individual concentration responses. The sensitivity to $\mathrm{PE}, \mathrm{ACh}$, and SNP was assessed by negative logarithm of the corresponding $\mathrm{EC}_{50}\left(\mathrm{pD}_{2}=-\log \mathrm{EC}_{50}(\mathrm{M})\right)$, and vasorelaxation (and its maximum) was expressed as the percentage of contraction induced by phenylephrine.

\section{Immunohistochemistry}

The immunoreactivity to caspase-3 (1:400; Novus Biologicals, Littleton, CO), caspase-8 (1:1000; Novus Biologicals, Littleton, CO), caspase-9 (1:50; Santa Cruz Biotechnology, Dallas, TX), caspase-12 (1:200; Novus Biologicals, Littleton, CO), myeloperoxidase (MPO) (1:200; Abcam, Cambridge, UK), and nitrotyrosine (1:200; MilliporeSigma, Burlington, MA) was assessed. Infiltrating neutrophils (MPO-labeled) were counted; caspase-3, caspase-8, caspase- 9 , caspase- 12 , and nitrotyrosine expression were semi-quantitatively assessed based on staining intensity and the distribution of the labeled target protein. The analysis was performed under a conventional light microscope in a blinded fashion. The intensity score values were given as follows: 0 , no positive staining; 1, weak staining; 2, intermediate staining; and 3, extensive staining, and an area score was assigned as follows: $1=$ up to $10 \%$ positive cells, $2=11-50 \%$ positive cells, $3=51-80 \%$ positive cells, and $4=$ more than $80 \%$ positive cells, using the ImageJ analysis system (NIH, MD, USA). The total score of each field was calculated as intensity score multiplied by area score (012). The evaluation was carried out in four random and nonoverlapping fields of the aorta, and the average value was calculated for each animal.

\section{Quantitative real-time polymerase chain reaction}

As previously reported $[29,30]$, the total RNA was isolated with the RNeasy Fibrous Tissue Mini Kit (Qiagen, Hilden, Germany). The RNA concentration and purity were determined by absorbance measurements at 230 $\mathrm{nm}, 260 \mathrm{~nm}$, and $280 \mathrm{~nm}$. cDNA synthesis was performed with the QuantiTect Reverse Transcription Kit (Qiagen, Hilden, Germany) using $250 \mathrm{ng}$ of isolated total RNA in a total volume of $20 \mu \mathrm{L}$. Quantitative real-time PCR was performed with the Light-Cycler480 system combining LightCycler480 Probes Master with Universal ProbeLibrary probes (Roche, Mannheim, Germany) (Online Table 1). The conditions for the qRT-PCR were as follows: $95^{\circ} \mathrm{C}$ for $10 \mathrm{~min}(1 \mathrm{cycle}), 95^{\circ} \mathrm{C}$ for $10 \mathrm{~s}, 60^{\circ} \mathrm{C}$ for $30 \mathrm{~s}$ (single; 45 -cycle quantification), and $40^{\circ} \mathrm{C}$ for $10 \mathrm{~s}$ ( 1 cycle). The reaction volume was $20 \mu \mathrm{L}$. The following targets were investigated: caspase-3, intercellular 
adhesion molecule (ICAM)-1 and vascular cell adhesion molecule (VCAM)-1. Sample quantifications were normalized to glyceraldehyde 3-phosphate dehydrogenase (GAPDH) expression, by using a pool of all cDNAs (positive calibrator). The evaluation was performed with the Light Cycler 480 SW 1.5 software (Roche, Mannheim, Germany).

\section{Statistical analysis}

The results were expressed as mean \pm standard error of the mean (SEM). Statistical analysis was performed using the GraphPad Prism 7.02 software (GraphPad Software, Inc., CA). Data was tested for normality using the Shapiro-Wilk test before statistical tests. The twosample student $t$ test was used to compare the means of sham and BD groups from normally distributed data, and a nonparametric Mann-Whitney test was applied if data were not normally distributed. In all other cases, one-way ANOVA followed by Tukey's post hoc test was applied for multiple comparisons. If the data were not normally distributed, the nonparametric Kruskal-Wallis test followed by Dunn's post hoc test was used. A value of $p<0.05$ was considered statistically significant.

\section{Results}

\section{Characterization of BD rat model}

\section{Effect of brain death on hemodynamic parameters}

Heart rate (342 \pm 6 vs. $395 \pm 8$ beats $/ \mathrm{min}, p<0.05)$, systolic blood pressure ( $63 \pm 1$ vs. $126 \pm 4 \mathrm{mmHg}, p<0.05)$, diastolic blood pressure $(41 \pm 2$ vs. $94 \pm 4 \mathrm{mmHg}, p<$ $0.05)$, mean arterial pressure $(48 \pm 1$ vs. $105 \pm 4 \mathrm{mmHg}$, $p<0.05)$, and pulse pressure $(22 \pm 1$ vs. $32 \pm 2 \mathrm{mmHg}$, $p<0.05)$ were significantly decreased in the BD group compared to the sham-operated rats.

\section{Effect of brain death on contractile and relaxant responses}

To examine the effects of brain injury on vascular functional changes, isolated organ bath technique was used. Compared with the sham-operated group, both maximum contractile responses to high $\mathrm{K}^{+}$-induced depolarization and adrenergic alpha-1 agonist PE were significantly higher in the BD group (Table 1, Fig. 2a, b). ACh induced a concentration-dependent relaxation in aortic rings precontracted with PE (Fig. 2c). Maximal endothelium-dependent relaxation $\left(R_{\max }\right)$ to $\mathrm{ACh}$ was significantly impaired in the aortic rings in the BD group compared with the sham-operated animals. Moreover, brain death significantly decreased aortic sensitivity $\left(\mathrm{pD}_{2}\right.$ value) to $\mathrm{ACh}$ (Table 1). Although maximum endothelium-independent vasorelaxation to SNP did not differ between the two groups, the concentrationresponse curve from $\mathrm{BD}$ aortas tended to be left-shifted compared to sham-operated rats (Table 1, Fig. 2d).

\section{Effect of brain death on neutrophil infiltration, nitro- oxidative stress, and apoptosis}

To determine whether brain death induction was associated with cellular changes in the aorta, we performed immunohistochemistry. Neutrophil infiltration, assessed by staining for MPO, was significantly higher in BD rings compared to the sham-operated rats (Fig. 3a). Detection of nitrotyrosine is regarded as a marker of nitrooxidative stress. Intense nitrotyrosine immunoreactivity was present in the $\mathrm{BD}$ group compared to controls (Fig. 3b). Analysis of apoptosis in aortic tissue also revealed that caspase- 3 , caspase- 8 , caspase- 9 , and caspase12 immunoreactivity was significantly higher after brain injury compared to the sham-operated animals (Fig. 3c-f).

\section{Effect of CM against IR injury in BD rats' aorta Characterization of the $C M$}

The characterization of soluble factors secreted by MSCs with antibody-based protein array analysis revealed that CM contained 39 of 90 proteins, including cytokines/ chemokines, growth factors, adhesion molecules, and other proteins. Among them, at least 23 factors are involved in apoptosis, inflammation, and oxidative stress (Table 2, Fig. 4).

\section{Effect of CM on contractile responses after IR injury}

Contractile responses to $\mathrm{KCl}$ were significantly impaired in the BD-IR group compared to BD rats, and CM had no effect (Table 2, Fig. 5a). Higher contractile responses to PE observed in the BD-IR aortas compared to the BD group were significantly reduced by CM (Table 1 , Fig. 5b). Additionally, increased aortic ring sensitivity $\left(\mathrm{pD}_{2}\right.$ value) to $\mathrm{PE}$ seen after IR injury in the $\mathrm{BD}$ group was significantly decreased by CM (Table 1 ).

Table 1 Quantitative analysis of vascular function

\begin{tabular}{llllllll}
\hline & $\mathrm{KCl}(\mathbf{g})$ & $\mathrm{PE}(\%$ of $\mathrm{KCl})$ & $\mathrm{pD}_{\mathbf{2}}$ to $\mathrm{PE}$ & $\boldsymbol{R}_{\max }$ to $\mathrm{ACh}(\%)$ & $\mathrm{pD}_{2}$ to $\mathrm{ACh}$ & $\boldsymbol{R}_{\max }$ to $\mathrm{SNP}(\%)$ & $\mathrm{pD} \mathbf{2}_{\mathbf{2}}$ to $\mathrm{SNP}$ \\
\hline $\mathrm{BD}$ & $4.4 \pm 0.1$ & $69 \pm 4$ & $6.8 \pm 0.1$ & $81 \pm 2$ & $7.1 \pm 0.1$ & $100 \pm 0$ & $9.4 \pm 0.1$ \\
$\mathrm{BD}-\mathrm{IR}$ & $2.7 \pm 0.2^{*}$ & $132 \pm 10^{*}$ & $7.1 \pm 0.1^{*}$ & $50 \pm 3^{*}$ & $6.7 \pm 0.1$ & $100 \pm 0$ & $9.1 \pm 0.1$ \\
$\mathrm{BD}-\mathrm{IR}+\mathrm{CM}$ & $2.8 \pm 0.1^{*}$ & $91 \pm 6^{*, \#}$ & $6.6 \pm 0.1^{\#}$ & $72 \pm 2^{\#}$ & $7.3 \pm 0.1^{\#}$ & $99 \pm 0$ & $9.3 \pm 0.1$ \\
\hline
\end{tabular}

$K C l$ potassium chloride, $P E$ phenylephrine, $A C h$ acetylcholine, $S N P$ sodium nitroprusside, $I R$ ischemia/reperfusion, $C M$ conditioned medium, $B D$ brain death, $R_{\text {max }}$ maximum relaxation, $p D_{2},-\log E C_{50} E C_{50}$ being the concentration of substance that elicited $50 \%$ of the maximum response. Values are means $\pm S E M$ ${ }^{*} p<0.05$ vs. $\mathrm{BD},{ }^{\#} p<0.05$ vs. BD-IR

$n=26-34$ rings from 7 to 9 rats 


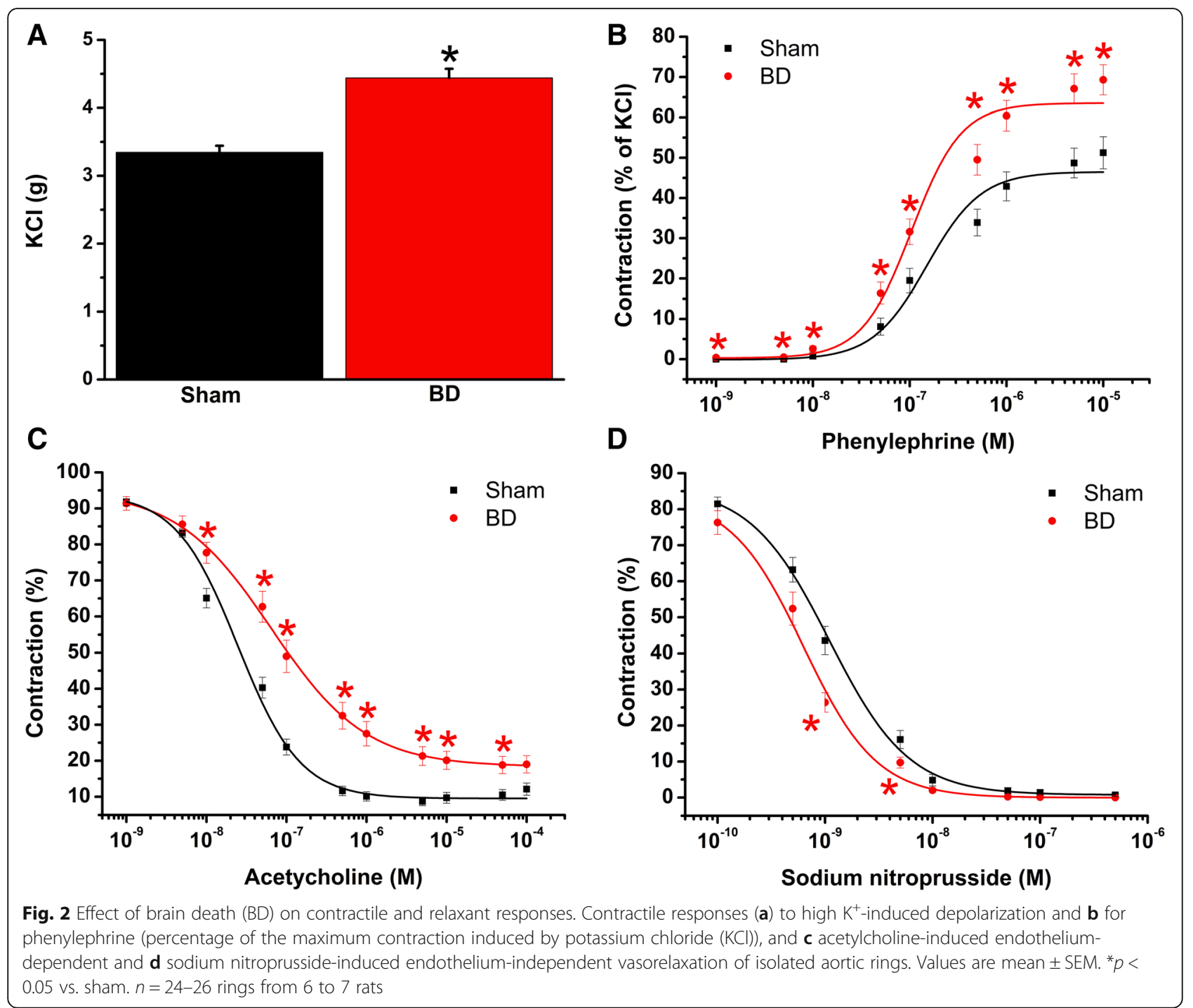

\section{Effect of CM on endothelium-dependent vasorelaxation after IR injury}

Decreased $R_{\max }$ to $\mathrm{ACh}$ in the BD-IR group compared to $\mathrm{BD}$ rats was significantly improved by the preservation of the aortic rings with $\mathrm{CM}$, indicating an amelioration of endothelial function (Table 2, Fig. 5c). Additionally, decreased aortic ring sensitivity to ACh (as expressed in $\mathrm{pD}_{2}$ value) seen after IR injury was significantly increased by CM (Table 1).

\section{Effect of CM on endothelium-independent vasorelaxation after IR injury}

Figure 4d shows the concentration-dependent vasorelaxation induced by SNP, an endothelium-independent vasodilator. Although maximal vasorelaxation to SNP did not differ among the experimental groups, the concentration-response curve in the aortas from BD-IR+
$\mathrm{CM}$ tended to be left-shifted compared to the BD-IR group (Table 2, Fig. 5d).

Effect of CM on neutrophil infiltration, nitro-oxidative stress, and apoptosis after IR injury

Immunohistochemical data showed that assessment of neutrophil infiltration by quantification of MPO-positive cell infiltration and immunoreactivity for nitrotyrosine, caspase-3, caspase-8, caspase- 9 , and caspase-12 with brown staining did not further increase in the aortic rings from the $\mathrm{BD}-\mathrm{IR}$ group compared to the $\mathrm{BD}$ rats (Fig. 6). However, the preservation of IR aortic rings with CM significantly lowered MPO-positive neutrophil infiltration and caspase-3, caspase-8, and caspase- 9 immunoreactivity compared with the BD-IR group and had a tendency toward lower nitrotyrosine and caspase-12 positivity (Fig. 6). 


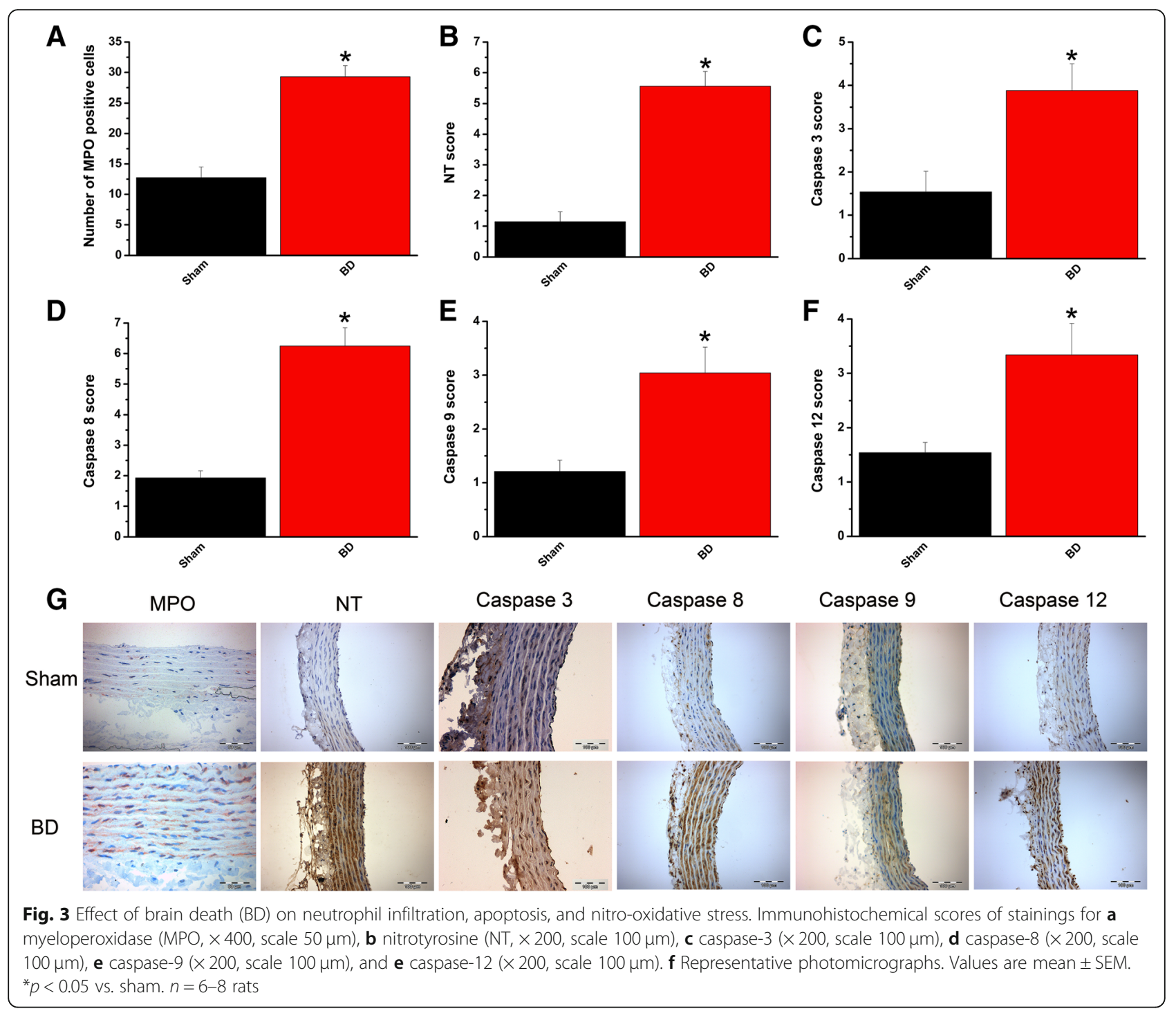

Table 2 List of 23 factors involved in apoptosis, inflammation, and oxidative stress in conditioned medium

\begin{tabular}{ll}
\hline Properties & Factors \\
\hline Anti-apoptotic & TIMP-1, growth hormone, growth hormone receptor, EG-VEGF (PK1), VEGF, VEGF-C, activin A, BDNF, FGF-BP \\
Pro-apoptotic & TRAIL, thrombospondin, TROY, Fas ligand/TNFSF6 \\
Anti-inflammatory & CXCR-4, MDC \\
Pro-inflammatory & CINC-2, CINC-3, FSL-1, MCP-1, MDC, MIF, MIP-1a, MMP-13, TLR4, Fas ligand/TNFSF6, CXCR-4 \\
Protection from oxidative stress & FGF-BP
\end{tabular}

TIMP-1 tissue inhibitors of metalloproteinases-1, EG-VEGF endocrine gland-derived vascular endothelial growth factor, PK1 prokineticin-1, VEGF vascular endothelial growth factor, VEGF-C vascular endothelial growth factor-C, BDNF brain-derived neurotrophic factor, FGF-BP fibroblast growth factor-binding protein, TRAIL tumor necrosis factor-related apoptosis-inducing ligand, TROY tumor necrosis factor receptor superfamily, member-19, TNFSF6 tumor necrosis factor superfamily, member-6, CXCR-4 C-X-C chemokine receptor type-4, MDC macrophage-derived chemokine, CINC cytokine-induced neutrophil chemoattractant, FSL-1 follostatinlike-1, MCP-1 monocyte chemoattractant protein-1, MIF macrophage migration inhibitory factor, MIP-1a macrophage inflammatory proteins 1-alpha, MMP-13 matrix metalloproteinase-13, TLR4 Toll-like receptor-4 


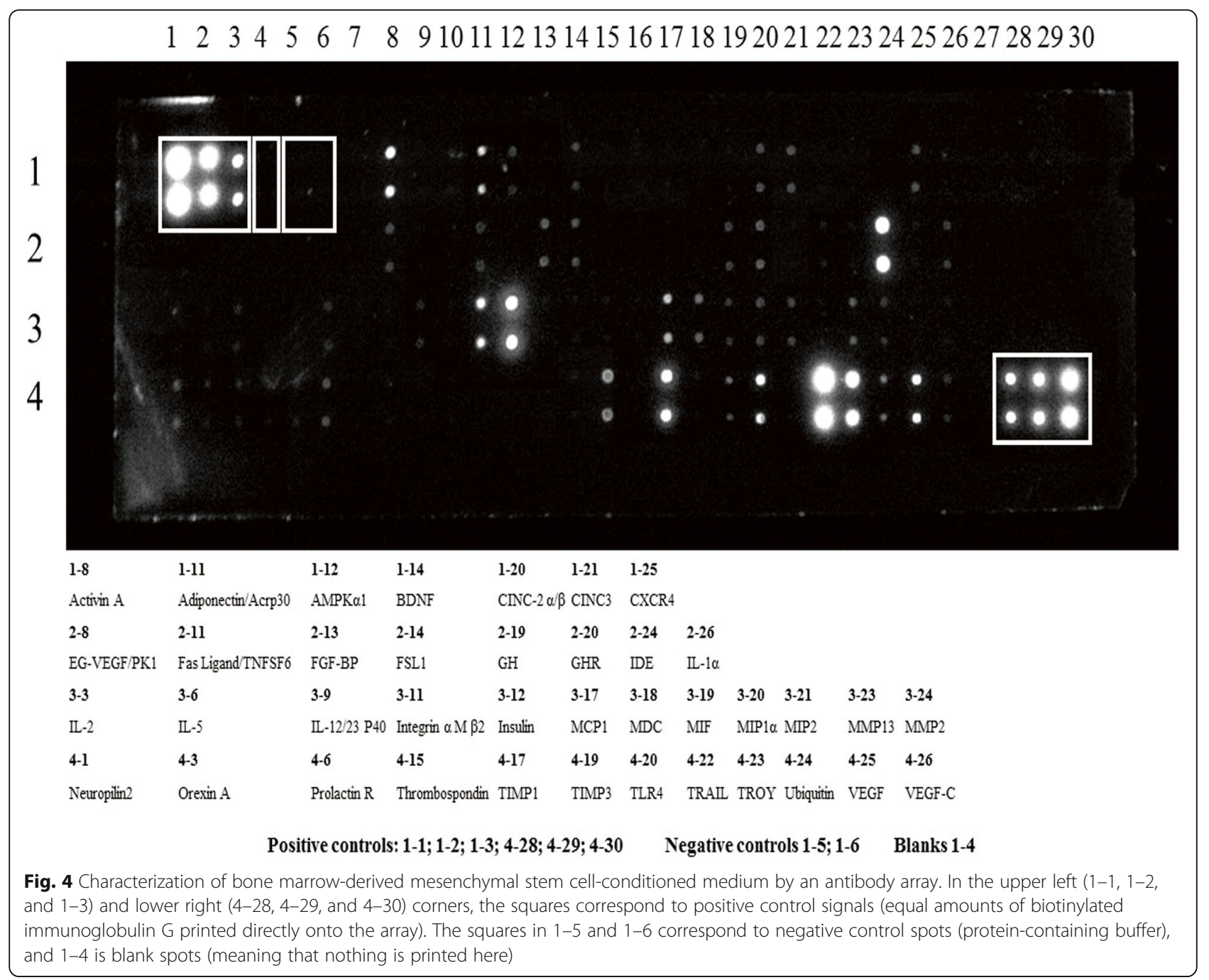

\section{Effect of CM on gene expression changes after IR injury} qRT-PCR revealed an increase in the gene expression of VCAM-1 and ICAM-1 in the BD-IR group compared to BD rats, which was significantly decreased by the preservation of aortic rings with CM (Fig. 7a, b). We observed a trend for increased caspase- 3 expression in the BD-IR group compared to $\mathrm{BD}$ and a decrease after $\mathrm{CM}$ treatment (Fig. 7c).

\section{Discussion}

In the present work, we tested the hypothesis that physiological saline solution-supplemented CM protects vascular grafts of BD rats from IR injury. To the best of our knowledge, this is the first study showing that the preservation of the aortic rings from $\mathrm{BD}$ rats with $\mathrm{CM}$ alleviates endothelial dysfunction following in vitro IR injury. $\mathrm{CM}$ has a preventive effect against endothelial dysfunction by lowering inflammatory response (through VCAM-1, ICAM-1 expression regression) and reducing caspase-mediated apoptosis.
Brain death in organ donors is a dynamic process with the following mechanisms associated with endothelial dysfunction: (a) the rapid rise of catecholamines, which inactivates endothelial relaxing substances (e.g., nitric oxide) and induces endothelin-1, a potent endotheliumderived contractile factor [31]; (b) hormone depletion, especially the decrease of thyroid hormones, which also results in impaired endothelium-dependent vasodilation [32]; (c) inflammatory cascade caused by endothelial activation after brain death [33]; and (d) the occurrence of oxidative stress, as well as apoptosis and nitro-oxidative stress-induced endothelial cell damage during brain death $[34,35]$. In the current study, we confirmed that brain death was associated with impaired hemodynamic parameters [26, 27] and showed vascular functional alterations (decreased endothelium-dependent vasorelaxation to $\mathrm{ACh}$, increased contractile responses to both $\mathrm{PE}$ and high $\mathrm{K}^{+}$-induced depolarization). BD-induced inflammation [36] may result in functional changes, as evidenced in the present study by elevation of MPO 


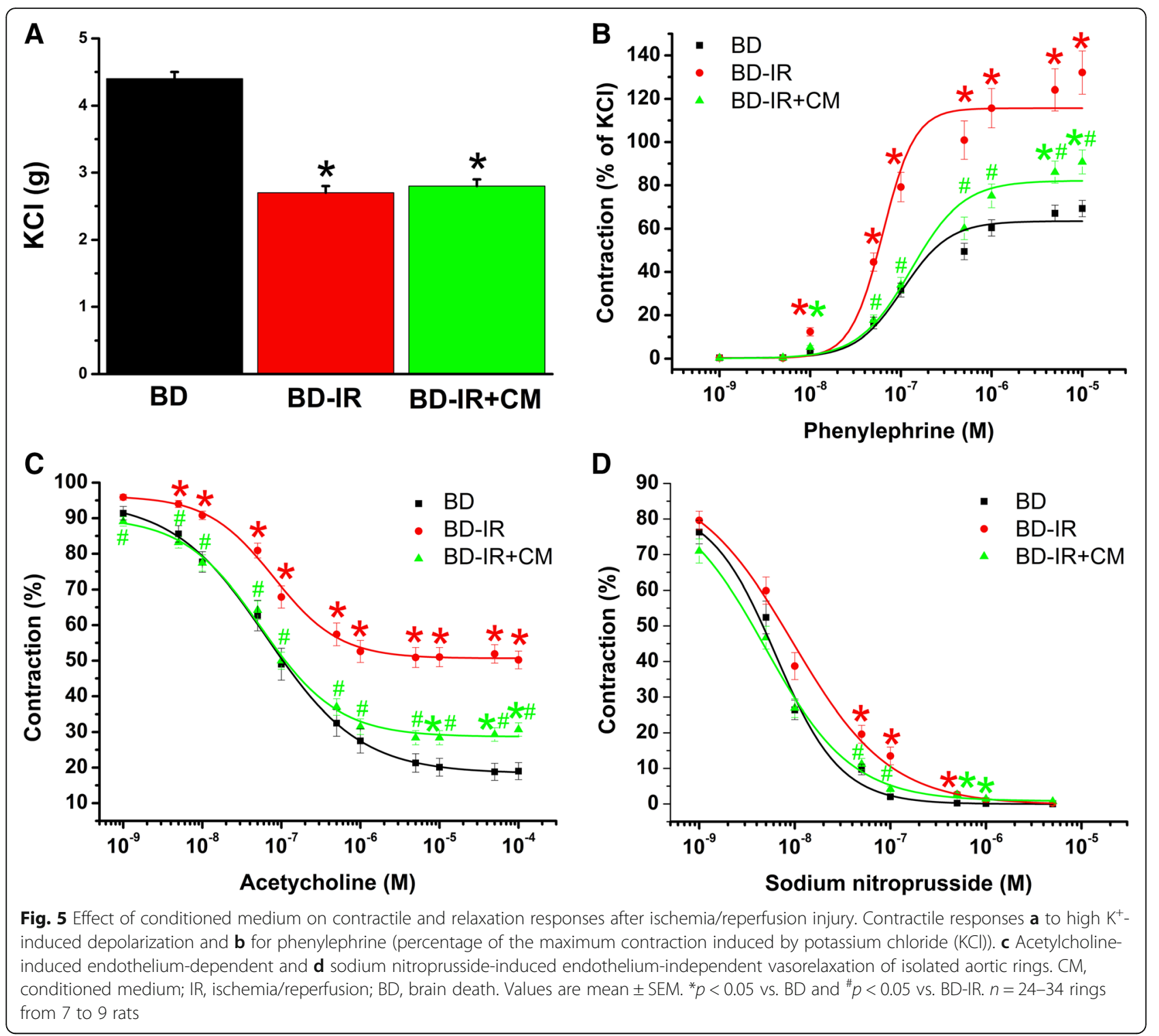

positivity in line with neutrophil infiltration. Furthermore, excessive generation of ROS and subsequent nitro-oxidative stress have been implicated in tissue injury following brain death. We showed that brain death led to increased formation of nitrotyrosine, a biomarker of nitrosative modification of proteins. Additionally, apoptosis can be triggered by three main signaling pathways, including extrinsic (death receptors) and intrinsic (mitochondria or the endoplasmic reticulum) pathways. We demonstrated that brain death-induced vascular functional alterations were also associated with caspasemediated apoptosis, shown by increased caspase-3, caspase-8, caspase- 9 , and caspase- 12 immunoreactivity, leading to excessive programmed cell death.

On the other hand, IR injury is an inevitable process during organ transplantation, which causes endothelial damage. Interestingly, even though IR injury impaired relaxant and contractile responses after brain death, the combination had no further effect on already high levels of MPO, nitrotyrosine, caspase-3, caspase-8, caspase-9, and caspase-12. In transplantation, currently, hearts are usually obtained from BD donors; however, more than a quarter of these potential donors must be excluded from transplantation due to ventricular dysfunction and contractility failure [37]. Therefore, new therapeutic strategies are required for protecting the endothelium against oxidative stress, apoptosis, and inflammation, as seen in brain death and IR injury, to optimize graft preservation and potentially increase the donor pool. In the present study, the preservation of aortic rings from BD rats with $\mathrm{CM}$ improved impaired endothelium-dependent vasorelaxation to ACh following IR injury. Bone marrow- 


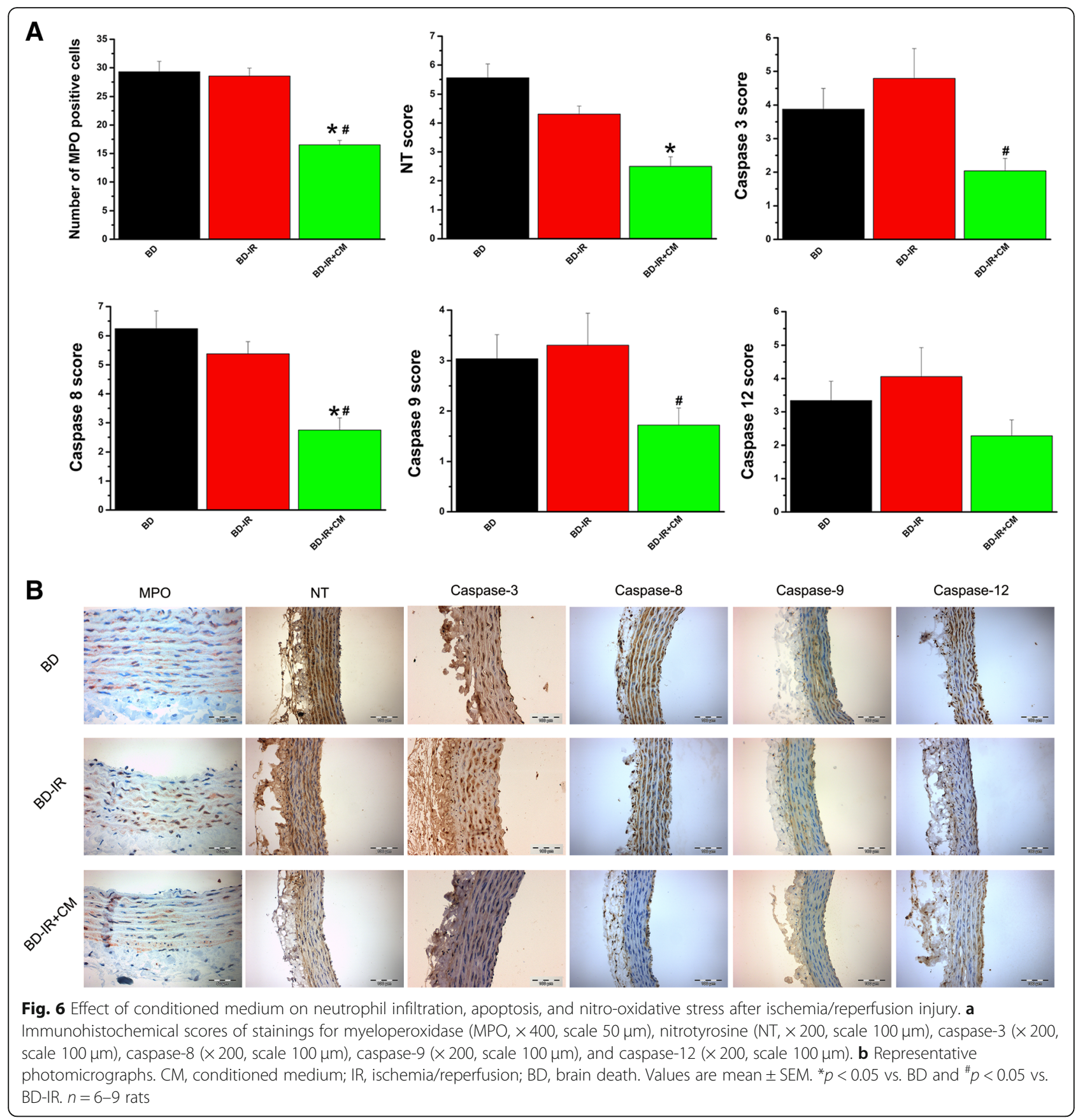

derived MSCs secrete many known mediators, including chemokines, cytokines, growth factors, and others that contribute to tissue protection. In the present work, among the 39 proteins identified in CM, some of them, such as tissue inhibitor of metalloproteinase (TIMP)-1, growth hormone, prokineticin, vascular endothelial growth factor (VEGF), and activin A factors, are potential mediators which may confer protection and improve functional outcome after vascular IR injury. It has been shown that VEGF regulates endothelial cell survival, and the inhibition of apoptosis may represent a major aspect of the regulatory activity of VEGF on the vascular endothelium [38]. Furthermore, in isolated hearts, coronary perfusion pressure alterations in response to ACh have been demonstrated in growth hormone-deficient rats [39].

Mechanisms underlying the vascular protective effects of CM after IR injury when using vascular grafts from BD donors

Coronary endothelial dysfunction has been described following brain death [3] and during cardiac transplantation-induced IR injury [40]. Inflammation, 

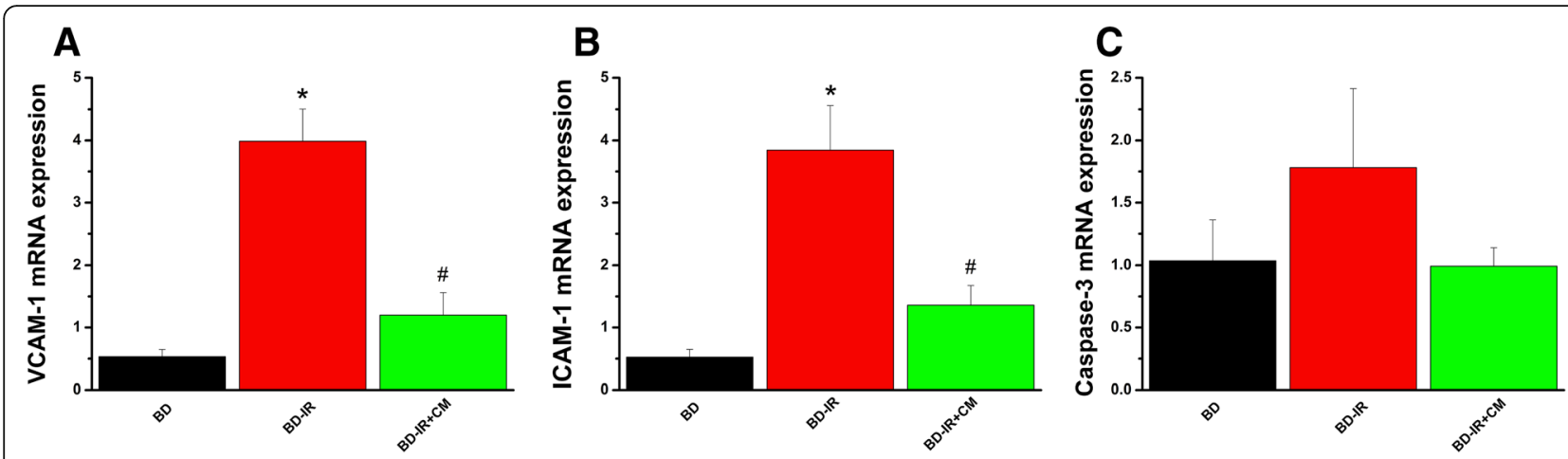

Fig. 7 Effect of conditioned medium on gene expression changes after ischemia/reperfusion injury. a Vascular cell adhesion molecule (VCAM)-1, b intercellular adhesion molecule (ICAM)-1, and c caspase-3. CM, conditioned medium; IR, ischemia/reperfusion; BD, brain death. Values are mean \pm SEM. ${ }^{*} p<0.05$ vs. BD and ${ }^{\#} p<0.05$ vs. BD-IR. $n=3-6$ rats

oxidative and nitrosative stress, and apoptosis-mediated cell death are the main responsible pathological factors. Enhanced ROS generation and activated neutrophils leading to apoptosis occur during brain death and cold ischemia.

Cellular damage induced by ischemia and aggravated by reperfusion activates an extensive inflammatory response. In the present study, the preservation of the aortic rings from $\mathrm{BD}$ rats with $\mathrm{CM}$ decreased the level of MPO following IR injury, the most abundant proinflammatory enzyme released upon neutrophil activation. Furthermore, increased gene expression of vascular inflammation-related specific adhesion molecules ICAM-1 and VCAM-1 following IR injury, reflecting endothelial dysfunction, has been lessened by CM.

The activation and adhesion of neutrophils to the endothelium is followed by a release of proinflammatory agents and by the production of excessive reactive nitrogen species and ROS. Mihm et al. showed that high nitrotyrosine concentrations, as a molecular footprint of peroxynitrite, may contribute to vascular endothelial dysfunction and concentration-dependent impairment of ACh maximal response [41]. Endothelial function can be assessed by the analysis of endothelial cells' responsiveness to the vasodilator ACh. In line with these observations, the preservation of BD-IR aortic rings with $\mathrm{CM}$ significantly improved impaired AChinduced endothelium-dependent vasorelaxation and showed a tendency to decrease nitrotyrosine immunoreactivity. In a rat model of diabetes mellitus-associated vascular endothelial dysfunction, MSCs-CM perfusion was shown to ameliorate compromised aortic vasodilation and alleviate oxidative stress in the aortas [42].

Another mechanism of reperfusion-linked tissue injury is apoptosis. Caspase- 8 , caspase- 9 , and caspase- 12 are crucial molecules of three apoptosis pathways, namely, death receptors-mediated extrinsic pathway, intrinsic pathway, and endoplasmic reticulum stress-mediated pathway, respectively, which subsequently activate caspase-3. The decreased caspase-3, caspase-8, and caspase- 9 immunoreactivity showed that $\mathrm{CM}$ reduced apoptosis in the aorta injured by brain death and IR injury. In line with these results, the mRNA caspase- 3 levels, the main downstream effector of caspase, showed a decreasing trend after the preservation of aortic rings with CM. TIMPs are inhibitors of matrix metalloproteinase (MMPs) but also have MMP-independent functions. It has been shown that exogenous TIMP-1 prevents endothelial cell apoptosis through the activation of cell survival pathways [43]. Furthermore, the aorta of endothelial-specific prokineticin receptor-1 deficient mice displayed progressive impairment of ACh mediated endothelium-dependent relaxation, because of decreased nitric oxide synthesis [44]. It should also be mentioned that both pro-apoptotic and anti-apoptotic proteins were detected in the $\mathrm{CM}$. We believe that the balance between pro- and anti-apoptotic factors in CM solution ensures tissue homeostasis, and its disruption may have adverse effects. It has also been reported that CM from multipotent stromal cells inhibits hypoxiainduced apoptosis and increases the survival of human aortic endothelial cells [45].

Even though we could not provide direct mechanistic evidence that the improved endothelial function was due to secreted factors by $\mathrm{CM}$, our study did show that neutrophil infiltration was attenuated; immunoreactivity against caspase-3, caspase- 8 , and caspase- 9 proteins was decreased; and ICAM-1 and VCAM-1 gene expression had regressed in vascular grafts from BD animals submitted to IR injury. In line with previous studies, our data suggest that the "cocktail" of several soluble factors secreted by bone marrow-derived MSCs acting together may contribute to tissue protection, thereby improving vascular graft function after IR injury. Further experimental research should be designed to elucidate the role of other factors identified in MSCs-CM. 
There are some limitations to our study. Firstly, it would have been more clinically relevant to investigate the effect of $\mathrm{CM}$ on coronary endothelial dysfunction after IR injury than on the aorta; however, this is due to size limitations. However, the dimension and structure of the rat thoracic aorta are close to the large mammals and to human coronary arteries. Secondly, our ex vivo vascular ring apparatus examines the vascular reactivity but did not involve non-aortic tissues, blood flow to the tissues, and activation of leukocytes, which is required to be translated into a clinically relevant in vivo situation. Thirdly, identification of key candidate proteins detected in CM would help to elucidate the mechanisms involved in the protective effect. However, we have no direct evidence at this point. Finally, it remains unclear if other pathways play an essential role in the beneficial effect of $\mathrm{CM}$ on vascular graft from $\mathrm{BD}$ rats submitted to IR injury.

\section{Conclusions}

In conclusion, the present study reveals that MSCs-CM significantly attenuates endothelial dysfunction against IR injury in the aorta of BD rats, in part, by lowering inflammatory response (through VCAM-1, ICAM-1 expression regression) and reducing caspase-mediated apoptosis. These likely do not represent the sole mechanism responsible for CM-mediated protection and further investigation is required to provide other possible mechanisms. From the clinical point of view, if hypothermic organ preservation could be improved, higher protection against both IR injury and brain death would be obtained, and the risk of posttransplant organ dysfunction would be reduced.

\section{Supplementary Information}

The online version contains supplementary material available at https://doi. org/10.1186/s13287-021-02166-3.

Additional file 1. : Online Table 1: Sequence of primers for real-time PCR and Universal Probe Library (UPL) probes.

\section{Abbreviations}

ACh: Acetylcholine; BD: Brain-dead; CM-MSCs: Conditioned medium from mesenchymal stem cells; D-MEM: Dulbecco's modified Eagle's medium; DPBS: Dulbecco's phosphate-buffered saline; $\mathrm{EC}_{50}$ : Concentration of substance that elicited $50 \%$ of the maximum response; ICAM-1: Intercellular adhesion molecule-1; IR: Ischemia/reperfusion; KCl: Potassium chloride; $\mathrm{KH}_{2} \mathrm{PO}_{4}$ : Potassium dihydrogen phosphate; $\mathrm{KHL}$ : Krebs-Henseleit; MMP: Matrix metalloproteinase; MPO: Myeloperoxidase; MSCs: Mesenchymal stem cells; $\mathrm{NaCl}$ : Sodium chloride; $\mathrm{Na}_{2} \mathrm{HPO}_{4}$ : Sodium hydrogen phosphate;

$\mathrm{NaOH}$ : Sodium hydroxide; $\mathrm{pD}_{2}$ : -logEC50; PE: Phenylephrine; $R_{\max }$ : Maximum endothelium-dependent relaxation; ROS: Reactive oxidative species: SEM: Standard error of the mean; SNP: Sodium nitroprusside; TIMP-1: Tissue inhibitor of metalloproteinase-1; VCAM-1: Vascular cell adhesion molecule-1; VEGF: Vascular endothelial growth factor

\section{Acknowledgements}

The technical assistance of Karin Sonnenberg, Lutz Hoffmann, Tobias Mayer and Patricia Kraft is gratefully acknowledged.

\section{Authors' contributions}

The study was conceived by SKI, PZ, and GS. SKI, PZ, YG, and SL were all involved in the performance of key experiments. SKI, PZ, and YG performed the data analysis. SKI and PZ were responsible for the manuscript writing. SKI, PZ, SL, PB, AAS, TR, MR, GV, MK, and GS revised the manuscript. All authors read and approved the final manuscript.

\section{Funding}

This study was supported by the Land Baden-Württemberg, Germany; by the Medical Faculty of the University of Heidelberg, Germany (Dr. Korkmaz-Icöz); and by the Scholarship of Guangzhou Elite Project (Mr. Zhou). Project no. NVKP_16-1-2016-0017 ("National Heart Program") has been implemented with support provided by the National Research, Development and Innovation Fund of Hungary, financed under the NVKP_16 funding scheme. The research was financed by the Thematic Excellence Programme (2020-4.1.1.-TKP2020) of the Ministry for Innovation and Technology in Hungary, within the framework of the Therapeutic Development and Bioimaging thematic programs of the Semmelweis University. Open Access funding enabled and organized by Projekt DEAL.

\section{Availability of data and materials}

All data generated or analyzed during this study are included in this published article and its supplementary information files.

Ethics approval and consent to participate

All procedures and handling of animals during the investigations were reviewed and approved by the Ethical Committee of the Land BadenWürttemberg for Animal Experimentation.

\section{Consent for publication}

Not applicable.

\section{Competing interests}

The authors declare that they have no competing interests.

\section{Author details}

'Department of Cardiac Surgery, Laboratory of Cardiac Surgery, University Hospital Heidelberg, INF 326, 69120 Heidelberg, Germany. ${ }^{2}$ Department of Cardiac Surgery, University Hospital Halle (Saale), Halle 06120, Germany.

${ }^{3}$ Heart and Vascular Center, Semmelweis University, Budapest 1122, Hungary.

Received: 16 June 2020 Accepted: 12 January 2021

Published online: 24 February 2021

\section{References}

1. Metra M, Ponikowski P, Dickstein K, McMurray JJ, Gavazzi A, Bergh CH, et al. Advanced chronic heart failure: a position statement from the Study Group on Advanced Heart Failure of the Heart Failure Association of the European Society of Cardiology. Eur J Heart Fail. 2007;9:684-94.

2. Hollenberg SM, Klein LW, Parrillo JE, Scherer M, Burns D, Tamburro P, et al. Coronary endothelial dysfunction after heart transplantation predicts allograft vasculopathy and cardiac death. Circulation. 2001;104:3091-6.

3. Szabo G, Buhmann V, Bahrle S, Vahl CF, Hagl S. Brain death impairs coronary endothelial function. Transplantation. 2002;73:1846-8.

4. Smith M. Physiologic changes during brain stem death--lessons for management of the organ donor. J Heart Lung Transplant. 2004;23:S217-22.

5. Bugge JF. Brain death and its implications for management of the potential organ donor. Acta Anaesthesiol Scand. 2009;53:1239-50.

6. Kuznetsov AV, Javadov S, Margreiter R, Grimm M, Hagenbuchner J, Ausserlechner MJ. The role of mitochondria in the mechanisms of cardiac ischemia-reperfusion injury. Antioxidants (Basel). 2019;8(10):454.

7. Schofield ZV, Woodruff TM, Halai R, Wu MC, Cooper MA. Neutrophils--a key component of ischemia-reperfusion injury. Shock. 2013;40:463-70.

8. Lemasters JJ, Bond JM, Chacon E, Harper IS, Kaplan SH, Ohata H, et al. The $\mathrm{pH}$ paradox in ischemia-reperfusion injury to cardiac myocytes. EXS. 1996; 76:99-114.

9. Kumar S, Kasseckert S, Kostin S, Abdallah Y, Schafer C, Kaminski A, et al. Ischemic acidosis causes apoptosis in coronary endothelial cells through activation of caspase-12. Cardiovasc Res. 2007;73:172-80. 
10. Parolari A, Rubini P, Cannata A, Bonati L, Alamanni F, Tremoli E, et al. Endothelial damage during myocardial preservation and storage. Ann Thorac Surg. 2002;73:682-90.

11. Sacchetti B, Funari A, Michienzi S, Di Cesare S, Piersanti S, Saggio I, et al. Self-renewing osteoprogenitors in bone marrow sinusoids can organize a hematopoietic microenvironment. Cell. 2007;131:324-36.

12. Price MJ, Chou CC, Frantzen M, Miyamoto T, Kar S, Lee S, et al. Intravenous mesenchymal stem cell therapy early after reperfused acute myocardial infarction improves left ventricular function and alters electrophysiologic properties. Int J Cardiol. 2006:111:231-9.

13. Shake JG, Gruber PJ, Baumgartner WA, Senechal G, Meyers J, Redmond JM, et al. Mesenchymal stem cell implantation in a swine myocardial infarct model: engraftment and functional effects. Ann Thorac Surg. 2002;73:1919-26.

14. Parekkadan B, Milwid JM. Mesenchymal stem cells as therapeutics. Annu Rev Biomed Eng. 2010;12:87-117.

15. Eggenhofer E, Benseler V, Kroemer A, Popp FC, Geissler EK, Schlitt HJ, et al. Mesenchymal stem cells are short-lived and do not migrate beyond the lungs after intravenous infusion. Front Immunol. 2012;3:297.

16. Toma C, Pittenger MF, Cahill KS, Byrne BJ, Kessler PD. Human mesenchymal stem cells differentiate to a cardiomyocyte phenotype in the adult murine heart. Circulation. 2002;105:93-8.

17. Vizoso FJ, Eiro N, Cid S, Schneider J, Perez-Fernandez R. Mesenchymal stem cell secretome: toward cell-free therapeutic strategies in regenerative medicine. Int J Mol Sci. 2017;18(9):1852.

18. Caplan Al, Dennis JE. Mesenchymal stem cells as trophic mediators. J Cell Biochem. 2006;98:1076-84.

19. Gnecchi M, He H, Liang OD, Melo LG, Morello F, Mu H, et al. Paracrine action accounts for marked protection of ischemic heart by Akt-modified mesenchymal stem cells. Nat Med. 2005;11:367-8.

20. Kinnaird T, Stabile E, Burnett MS, Shou M, Lee CW, Barr S, et al. Local delivery of marrow-derived stromal cells augments collateral perfusion through paracrine mechanisms. Circulation. 2004;109:1543-9.

21. Angoulvant D, Ivanes F, Ferrera R, Matthews PG, Nataf S, Ovize M. Mesenchymal stem cell conditioned media attenuates in vitro and ex vivo myocardial reperfusion injury. J Heart Lung Transplant. 2011;30:95-102.

22. Timmers L, Lim SK, Arslan F, Armstrong JS, Hoefer IE, Doevendans PA, et al. Reduction of myocardial infarct size by human mesenchymal stem cell conditioned medium. Stem Cell Res. 2007:1:129-37.

23. Korkmaz-Icoz S, Li S, Huttner R, Ruppert M, Radovits T, Loganathan S, et al. Hypothermic perfusion of donor heart with a preservation solution supplemented by mesenchymal stem cells. J Heart Lung Transplant. 2019; 38:315-26.

24. Korkmaz-Icoz S, Li K, Loganathan S, Ding Q, Ruppert M, Radovits T, et al. Brain-dead donor heart conservation with a preservation solution supplemented by a conditioned medium from mesenchymal stem cells improves graft contractility after transplantation. Am J Transplant. 2020;20: 2847-56.

25. Korkmaz-Icoz S, Li S, Huttner R, Ruppert M, Radovits T, Loganathan S, et al. Hypothermic perfusion of donor heart with a preservation solution supplemented by mesenchymal stem cells. J Heart Lung Transplant. 2019; 38:315-26

26. Li S, Korkmaz S, Loganathan S, Radovits T, Hegedus P, Karck M, et al. Short and long-term effects of brain death on post-transplant graft function in a rodent model. Interact Cardiovasc Thorac Surg. 2015;20:379-86.

27. Li S, Korkmaz-Icoz S, Radovits T, Ruppert M, Spindler R, Loganathan S, et al Donor preconditioning after the onset of brain death with dopamine derivate n-octanoyl dopamine improves early posttransplant graft function in the rat. Am J Transplant. 2017;17:1802-12.

28. Veres $G$, Hegedus P, Barnucz E, Zoller R, Radovits T, Korkmaz S, et al. Addition of vardenafil into storage solution protects the endothelium in a hypoxia-reoxygenation model. Eur J Vasc Endovasc Surg. 2013;46:242-8.

29. Korkmaz S, Atmanli A, Li S, Radovits T, Hegedus P, Barnucz E, et al. Superiority of zinc complex of acetylsalicylic acid to acetylsalicylic acid in preventing postischemic myocardial dysfunction. Exp Biol Med. 2015;240: 1247-55.

30. Korkmaz-Icoz S, Atmanli A, Radovits T, Li S, Hegedus P, Ruppert M, et al. Administration of zinc complex of acetylsalicylic acid after the onset of myocardial injury protects the heart by upregulation of antioxidant enzymes. J Physiol Sci. 2016;66:113-25.

31. Stankevicius $E_{1}$ Kevelaitis $E_{1}$ Vainorius $E_{1}$ Simonsen $U$. Role of nitric oxide and other endothelium-derived factors. Medicina. 2003;39:333-41.
32. Vargas F, Fernandez-Rivas A, Garcia Estan J, Garcia del Rio C. Endotheliumdependent and endothelium-independent vasodilation in hyperthyroid and hypothyroid rats. Pharmacology. 1995;51:308-14.

33. Kusaka M, Pratschke J, Wilhelm MJ, Ziai F, Zandi-Nejad K, Mackenzie HS, et al. Activation of inflammatory mediators in rat renal isografts by donor brain death. Transplantation. 2000;69:405-10.

34. Stiegler $P$, Sereinigg M, Puntschart A, Bradatsch A, Seifert-Held T, Wiederstein-Grasser I, et al. Oxidative stress and apoptosis in a pig model of brain death (BD) and living donation (LD). J Transl Med. 2013;11:244.

35. Konukoglu D, Uzun H. Endothelial dysfunction and hypertension. Adv Exp Med Biol. 2017:956:511-40.

36. Watts RP, Thom O, Fraser JF. Inflammatory signalling associated with brain dead organ donation: from brain injury to brain stem death and posttransplant ischaemia reperfusion injury. J Transplant. 2013;2013:521369.

37. Szabo G. Physiologic changes after brain death. J Heart Lung Transplant. 2004;23:S223-6.

38. Gerber HP, McMurtrey A, Kowalski J, Yan M, Keyt BA, Dixit V, et al. Vascular endothelial growth factor regulates endothelial cell survival through the phosphatidylinositol 3'-kinase/Akt signal transduction pathway. Requirement for Flk-1/KDR activation. J Biol Chem. 1998;273:30336-43.

39. De Gennaro CV, Rossoni G, Bonacci D, Ciceri S, Cattaneo L, Muller E, et al. Worsening of ischemic damage in hearts from rats with selective growth hormone deficiency. Eur J Pharmacol. 1996;314:333-8.

40. Treasure CB, Vita JA, Ganz P, Ryan TJ Jr, Schoen FJ, Vekshtein VI, et al. Loss of the coronary microvascular response to acetylcholine in cardiac transplant patients. Circulation. 1992;86:1156-64.

41. Mihm MJ, Jing L, Bauer JA. Nitrotyrosine causes selective vascular endothelial dysfunction and DNA damage. J Cardiovasc Pharmacol. 2000;36: 182-7.

42. Yuan Y, Shi M, Li L, Liu J, Chen B, Chen Y, et al. Mesenchymal stem cellconditioned media ameliorate diabetic endothelial dysfunction by improving mitochondrial bioenergetics via the Sirt1/AMPK/PGC-1alpha pathway. Clin Sci. 2016;130:2181-98.

43. Boulday G, Fitau J, Coupel S, Soulillou JP, Charreau B. Exogenous tissue inhibitor of metalloproteinase-1 promotes endothelial cell survival through activation of the phosphatidylinositol 3-kinase/Akt pathway. Ann N Y Acad Sci. 2004;1030:28-36.

44. Nebigil CG. Updates on endothelial functions of proangiogenic prokineticin. Hypertension. 2016;68:1091-7.

45. Hung SC, Pochampally RR, Chen SC, Hsu SC, Prockop DJ. Angiogenic effects of human multipotent stromal cell conditioned medium activate the PI3KAkt pathway in hypoxic endothelial cells to inhibit apoptosis, increase survival, and stimulate angiogenesis. Stem Cells. 2007;25:2363-70.

\section{Publisher's Note}

Springer Nature remains neutral with regard to jurisdictional claims in published maps and institutional affiliations.

Ready to submit your research? Choose BMC and benefit from:

- fast, convenient online submission

- thorough peer review by experienced researchers in your field

- rapid publication on acceptance

- support for research data, including large and complex data types

- gold Open Access which fosters wider collaboration and increased citations

- maximum visibility for your research: over $100 \mathrm{M}$ website views per year

At $\mathrm{BMC}$, research is always in progress.

Learn more biomedcentral.com/submission 